\title{
The Lightfall and the Symbolic Function of the Hyperbolic Paraboloid Surface
}

\author{
Eran Neuman ${ }^{1}$
}

Published online: 13 October 2016

(C) Kim Williams Books, Turin 2016

\begin{abstract}
The paper discusses the symbolic function of the hyperbolic paraboloid surface in Preston Scott Cohen's design of the Lightfall at Tel Aviv Museum of Art and its precedents. While analysing several examples of the use of the hyperbolic paraboloid surface in architecture, the paper proposes three modes of symbolic use of the surface: operative, demonstrative and figurative.
\end{abstract}

\section{Introduction}

In 2011, the Tel Aviv Museum of Art opened its new wing, the Herta and Paul Amir Building (Fig. 1). Designed by the American architect Preston Scott Cohen, the building is constituted of an external angulated envelope, an internal centerpiece that Cohen named the Lightfall, and galleries that link between the external surface and the internal centerpiece. Although equally important and exquisite in their forms, the Lightfall drew more attention than the external envelope. This might be because Cohen highlighted the complexity of the centerpiece as an organizational atrium. It might be also due to the ways in which the shape was conceived and executed. Rising to a height of 26.5 meters, the Lightfall is composed of hyperbolic paraboloid surfaces positioned in various angles in relation to one another.

In the following paper, I would like to discuss my claim that the significance of the Lightfall goes beyond its shape and form and beyond its mathematical idea. Over the years, the hyperbolic paraboloid surface has been implemented in many ways. Each implementation carried significance beyond the structural and mathematical realm. The Lightfall is not different in that respect. In this essay, I

Eran Neuman

eneuman@post.tau.ac.il

1 Azrieli School of Architecture, Tel Aviv University, Haim Levanon St., Ramat Aviv, Tel Aviv 69978, Israel 


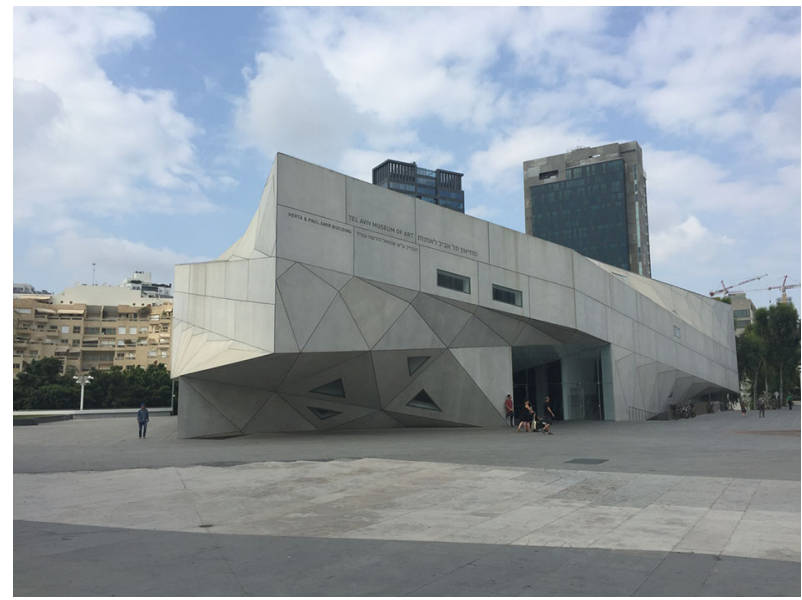

Fig. 1 Tel Aviv Museum of Art, the Herta and Paul Amir Building. Architect: Preston Scott Cohen

would like to propose a discussion of three different ways in which the surface is used as a symbol; each way stems from a different cultural condition and each represents a different meaning. Together, they constitute a comprehensive understanding of symbolic use of the mathematical shape.

I will start with a discussion of Cohen's Lightfall as an operative symbol. Then, by referring to two other prominent examples of the use of the hyperbolic paraboloid surface-first, to Vladimir Grigoryevich Shukhov's groundbreaking installation of the hyperbolic paraboloid surface in a tower at the All-Russia Industrial and Art Exhibition in Nizhny Novgorod in 1896, and second, to Le Corbusier and Iannis Xenakis' use of hyperbolic paraboloid surfaces in the Assembly Hall in Chandigarh and in the Philips Pavilion at Expo 58 in Brussels-I will expand on the symbolic role of hyperbolic paraboloid surfaces in architecture.

\section{The Lightfall and the Operative Symbolism of the Hyperbolic Paraboloid Surface}

Cohen, a professor of architecture at Harvard University's Graduate School of Design and a former chair of its Masters in Design program, evolved out of the academic sphere. His architectural ideas, mostly about contested geometries, were developed in these circumstances (Cohen 2001). It is not surprising, then, that Cohen often related his work to precedents in architectural history. Thus, he often compares the Herta and Paul Amir Building to Los Laboratorios, a building designed by the Spanish architect Miguel Fisac that was inaugurated in Madrid in 1968 (Cohen 2011). Fisac, who was a master of modern architecture and one of Spain's leading architects in the second half of the twentieth century, planned the building as an office and storage facility for the medical company Jorba. Cohen refers to this building and compares it to the new wing of the Tel Aviv Museum of Art because both he and Fisac used hyperbolic paraboloid surfaces, or hypars, in their buildings. 
The paraboloid is a mathematical equation that generates quadric surfaces of two types: elliptic and hyperbolic. The former constitutes on a shape of an oval cup. It has a maximum or minimum point. Its system is based on three axes $\mathrm{x}, \mathrm{y}$ as used in the equation: $\mathrm{z} / \mathrm{c}=\mathrm{x}^{2} / \mathrm{a}^{2}+\mathrm{y}^{2} / \mathrm{b}^{2}$. The hyperbolic paraboloid, or hypar, is a doubly ruled surface, usually in the shape of a saddle. Its coordinate system in also based in three axes, this time manifested in the equation: $\mathrm{z} / \mathrm{c}=\mathrm{y}^{2} / \mathrm{b}^{2}-\mathrm{x}^{2} / \mathrm{a}^{2}$ (Flügge 2013).

Fisac used the hypars to connect the various floors in the upper part of the building. The lower part is a two-story boxy structure, while from the third floor up, the building is morphologically more complex (Barrallo and Sánchez-Beitia 2011: 70-71). The floors are rotated at 90-degree angles in relation to one another so that a straight wall would not be able to connect them and create the necessary envelope for the building. The curved surface of the hyperbolic paraboloid provided a solution. It could stretch from one floor, rotate and reach the other floor in a way that would create the desired envelope. Between each floor, Fisac used eight hyperbolic paraboloid surfaces, two in each facet of a surface that connects the two floors. The outcome was visually impressive; it resembled a pagoda, which indeed became the building's nickname.

Similar to Fisac, Cohen used the hyperbolic paraboloid surfaces to connect architectural functions that are located on different levels. Yet whereas Fisac used hypars as external connectors and envelopes of the floors, Cohen used them to connect internal parts, namely, the galleries within the museum building (Fig. 2). As a matter of fact, Cohen initially started his design with a rectangular building, composed of several galleries stacked on top of each other. Then he shifted the galleries, similar to Fisac's shifting of the various floors in Los Laboratorios (Fig. 3). This shifting created the curved hyperbolic paraboloid surfaces that function as the internal facets of the galleries.

Yet unlike Fisac, Cohen did not maintain this condition. He detached the internal hyperbolic paraboloid surfaces from the galleries and left them independent so they could function as a centerpiece, which he named the Lightfall. At this point, the
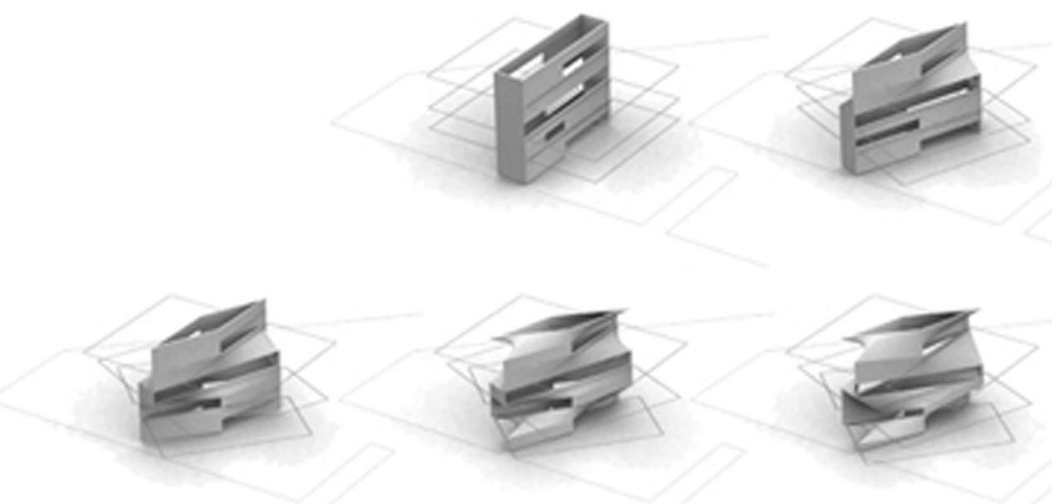

Fig. 2 Lightfall, design process 
Fig. 3 Lightfall, interior view

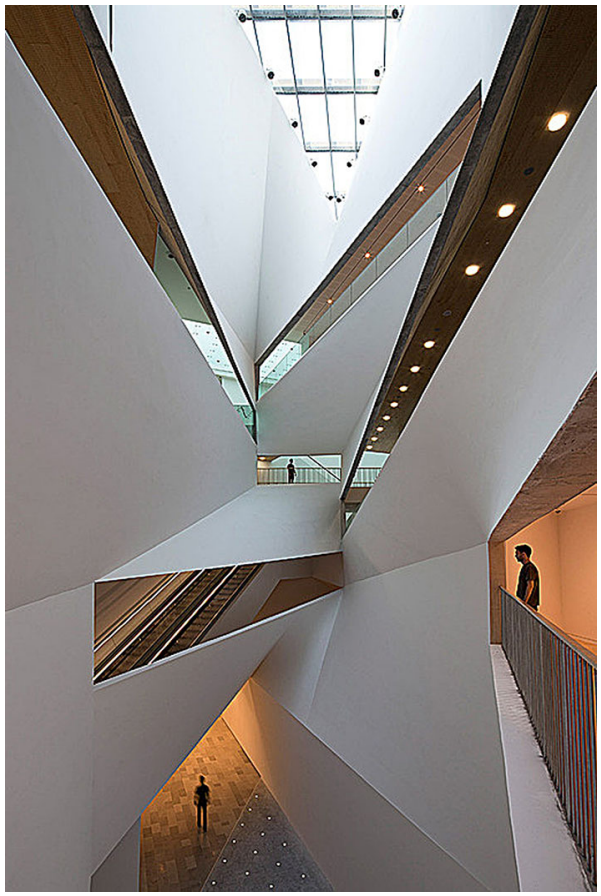

internal hyperbolic paraboloid surfaces lost their enveloping role and became reflectors of light, allowing natural light to penetrate the building's core along the entire 26.5-m height of the Lightfall, from its uppermost point in the ceiling to its lowest point on the bottom floor. In between the centerpiece and the galleries, Cohen inserted a circulation system and created what could be seen as a reference to typical museum typology: galleries that are organized in the building's periphery, an atrium in the center (in Cohen's case, the Lightfall), and circulation in between.

Cohen's detachment of the internal hyperbolic paraboloid surfaces from the galleries reflects his wish to maintain the nature of the galleries as white boxes. Had he left the internal hyperbolic paraboloid surfaces to form one of the galleries' walls, they would have changed the nature of the galleries and dominated the space in a way that might interfere with the art on display. Thus, Cohen only occasionally let the Lightfall penetrate the galleries, in a way that would not dominate the space. In that respect, Cohen was consistent with some of his other designs. Similar to the Torus House in Old Chatham, New York, that he designed in 1998 (Fig. 4a, b) or the Nanjing Performing Arts Center (2007), in the Herta and Paul Amir Building, Cohen pays tribute to ideas of modern architecture through his maintenance of the white box, applying modern architectural building schemes while interpreting them using complex morphology. In the new museum wing, the galleries are principally white boxes, and the Lightfall provides the contemporary intervention.

Yet the relationship between the modern architectural schemes (the white box spaces in the museum, the rectangular rooms in the Torus House) to which Cohen refers and the implementation of the new morphology is not simple. Cohen kept the 
a

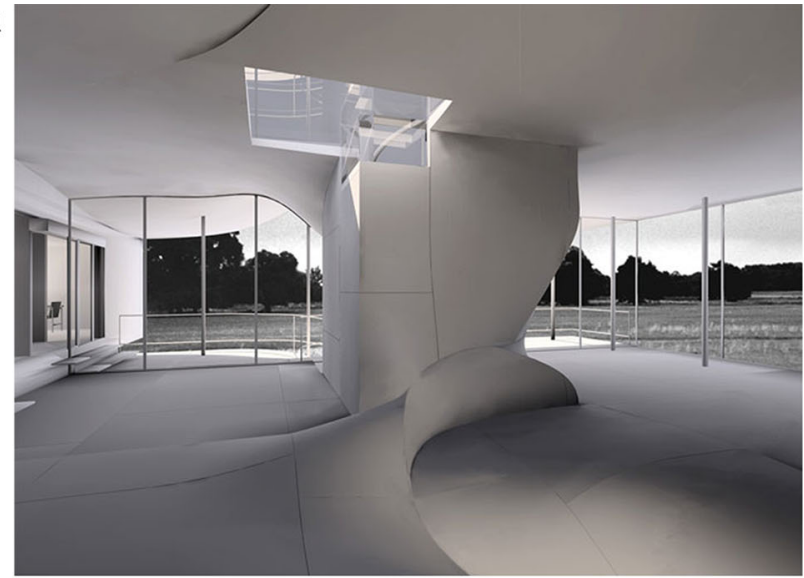

b

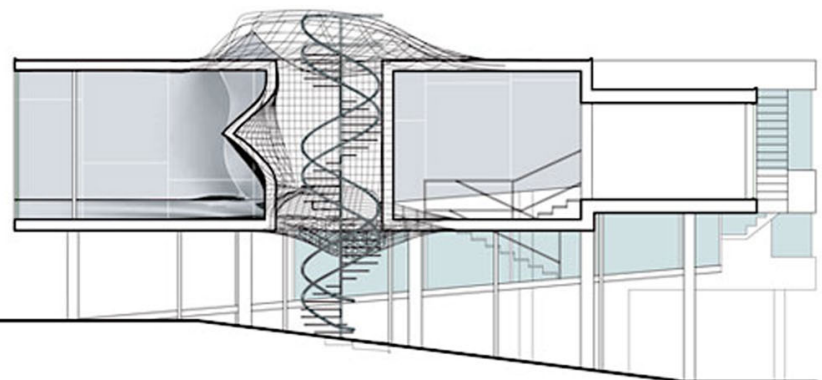

Fig. 4 a Torus House. Architect: Preston Scott Cohen. b Torus House, section

white boxes and the contemporary interventions in constant interplay; at the Tel Aviv Museum of Art, for instance, the physical detachment of the contemporary intervention, i.e., the Lightfall's hyperbolic paraboloid surfaces, does not conceptually detach it from the galleries. Since these hyperbolic paraboloid surfaces were determined by the shifting of the rotating galleries, they always retain some reference to the galleries. In fact, the surfaces are positioned in relation to the galleries such that they become indexes for the spatial organization of the galleries themselves. Theoretically, visitors circulating around the Lightfall can figure out the location of every gallery according to the hyperbolic paraboloid surface next to which they are walking. This is the moment when the Lightfall's hyperbolic paraboloid surfaces become a symbol.

When creating the Lightfall, Cohen's intention was not that it should serve as a sign for the galleries' location. Rather, he was seeking a way to create a unique spatial relationship between the hyperbolic paraboloid surfaces and the galleries, and above all, to let light "fall" into the building while bouncing from one surface to another (Cohen 2007). Nevertheless, in their new position, the surfaces that compose the Lightfall provide a symbolic function beyond their function as reflectors of light. Starting as a geometrical maneuver, i.e. a composition of various 
hypars to create the Lightfall, and then receiving a poetic signification, when the hypars were framed as a Lightfall, the hyperbolic paraboloid surfaces in the museum's new wing were imbued with a linguistic function, to serve as an index, a sign that indicates the visitors' location in the museum space.

In that respect, Cohen created a dual role for the Lightfall's hyperbolic paraboloid surfaces. On the one hand, as argued, they function as indexes within the museum's building space. Yet at the same time, since the Lightfall is morphologically exquisite, it has become the symbol of the museum. This is apparent in the museum's many publications in various media, and in the overall perception of the Lightfall by museum staff. The Lightfall is always in the forefront of the museum's public image; indeed, many scholars have already referred to it when writing about the museum (Tel Aviv Museum of Art 2016). Harvard University Prof. Antoine Picon, for instance, used an image of the Lightfall for the cover of his book Digital Culture in Architecture (Picon 2010), in which he discusses it in relation to digital architectural design and production. Prof. Sylvia Lavin of the University of California, Los Angeles, also discussed the Lightfall in relation to intimacy and internality in her book Kissing Architecture (Lavin 2011).

For Lavin, "the Lightfall is an intruder in the museum that causes a conceptually constituted interior to emerge. The core captures, moves, and shapes light while its exotic contours hold together and intensify these luminous and always changing effects" (Lavin 2011: 70). She views the Lightfall as not only an interior space that emerged out of the building's design and condition, but as an exotic shape, one may say hyperbolic paraboloid, which intensifies the fall of light.

Thus, the symbolic function of the Lightfall is different than that of the hyperbolic paraboloid surfaces of Los Laboratorios. In Fisac's building, the hypars' symbolic function ends with their visual reference to another architectural typology, the pagoda. The hypars function externally to create the building's image; internally, the walls that connect the floors have almost no additional function, certainly not a symbolic one related to the orientation or perception of the building. Fisac's hyperbolic paraboloid surfaces are an emblem, not a sign. With Cohen's use of the surfaces, they become both an emblem of the museum and a sign for the ways in which the museum should be used; the surfaces turn into an operative symbol that directs us and shows us ways to utilize the building. The extensive use of the Lightfall in the museum's publications and by many scholars testifies to its role as an emblem, similar to that of the hyperbolic paraboloid surfaces in the Pagoda building. Their function in the museum as indicators, however, marks their role as a sign.

\section{Vladimir Shukhov's Hyperbolic Paraboloid Tower and the Symbolic Demonstration of a Structure}

Russian architect and engineer Vladimir Shukhov made the first-ever use of hyperbolic paraboloid surfaces in a structure when he planned a water tower using conoid hyperbolic paraboloid surfaces for the All-Russia Industrial and Art Exhibition held in Nizhny Novgorod in 1896 (English 2005) (Fig. 5). As was common among the industrializing nations that organized many huge fairs and 
exhibitions during the nineteenth century, the European nations were keen to show off their overall progress and latest innovations in technology and engineering. The reference to building technologies was only natural for them. For example, several years before the All-Russia Industrial and Art Exhibition, the French erected the Eiffel Tower as a symbol of their ingenuity for the Exposition Universelle held in Paris in October 1889 (Zalivako 2009). Gustave Eiffel, a graduate of one of the most prestigious French engineering institutions, École Centrale des Arts et Manufactures, and an accomplished builder with several bridges in Europe under his belt, was chosen for the task. Towering over Paris, the eye-catching structure was the entrance to the exhibition and revealed France's engineering abilities in a way that no one could miss (Bennett 1994).

Similarly, the Russians wanted to showcase their innovative prowess in technology and engineering, and asked Shukhov to design a tower for the exhibition in Nizhny Novgorod. Shukhov had already amassed some experience with designing structures for world fairs after working on the Russian pavilion for the United States Centennial International Exhibition held in Philadelphia in 1876. He was well aware of the impact that such a structure was meant to make. For the All-Russia Industrial and Art Exhibition, he sought to build a tower incorporating hyperbolic paraboloid geometry, which had never before been put into practical use in architecture (Picon 1997). The tower was planned to support a water tank on top

Fig. 5 Water Tower. Architect: Vladimir Shukhov

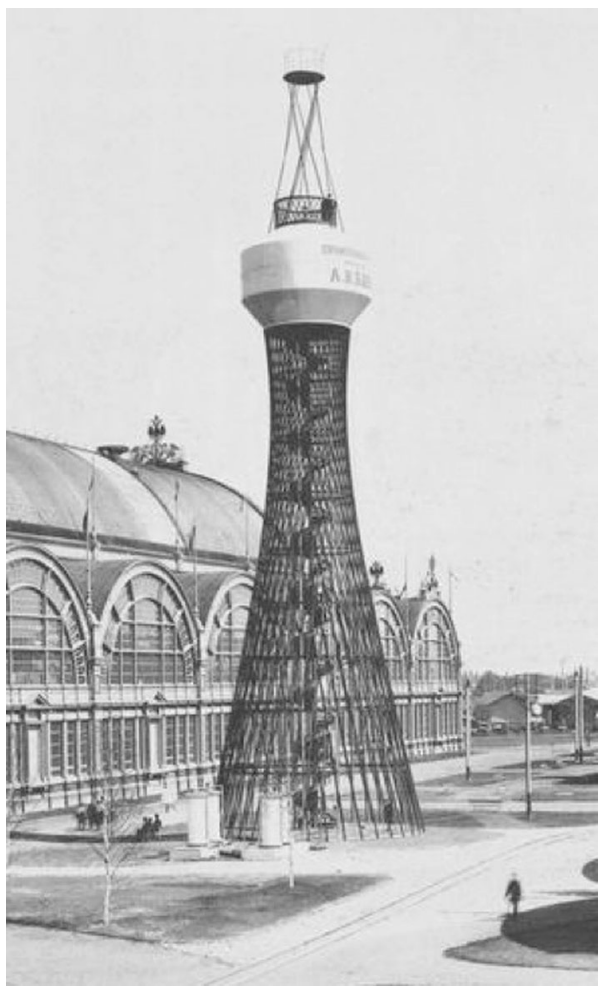


so Shukhov had to test the construction properties of a hyperbolic paraboloid structure and its ability to carry a heavy load.

Shukhov was inspired to erect such a tower by the Russian mathematician Nikolai Ivanovich Lobachevsky. A native of Nizhny Novgorod, Lobachevsky developed the formula of the hyperbolic paraboloid surface in the 1820s and 1830s, shortly before Shukhov was born (Papadopoulos 2010). Lobachevsky tried to refute Euclid's fifth postulate that claims that for any line or point not on the line, only one parallel line through the point intersecting the line can exist. Lobachevsky showed that in hyperbolic geometry, several parallel lines through the point intersecting the line can exist. Concurrently, the Italian mathematician Eugenio Beltrami was also trying to refute Euclid's fifth postulate (Kolmogorov and Yushkevich 1996). Beltrami showed that non-Euclidean geometry could be articulated on a negatively curved surface and on a pseudosphere. Lobachevsky and Beltrami, and later János Bolyai, were expanding the work of the German mathematician Carl Friedrich Gauss, who had started exploring negative curves. Gauss developed non-Euclidian topological geometry while trying to explore the mathematical function of curvilinear surfaces. Lobachevsky referred to Gauss' work and in 1830 published the formula of the hyperbolic paraboloid surface in his essay "A Concise Outline of the Foundations of Geometry" (Lobachevsky 1830). Here, Lobachevsky showed that for any given point outside a specific line more than one line can run parallel. A few years later, in 1868, Beltrami published his essay "Saggio di interpretazione della geometria non-euclidea," (Beltrami 1868) which in principle describes ideas similar to those of Lobachevsky about the non-Euclidean surface. Without knowing of the work of Lobachevsky, Bolyai also developed a theory that refuted Euclid's fifth postulate. In 1848, he published his treatise on hyperbolic geometry (Gray 2004).

Lobachevsky's, Bolyai's and Beltrami's attempts to demonstrate the existence of several lines that can run through a point outside any given line, all of which can be parallel to the given line, set the foundation for the hyperbolic paraboloid surface. Shukhov understood that Lobachevsky's ideas were not only theoretical, existing solely within an abstract mathematical context. The spherical condition of topological geometry paralleled the spherical shape of the universe and hence, for Shukhov, could be applied in built form. In the late nineteenth century he started experimenting with the construction of hyperbolic paraboloid structures, and the exhibition in Nizhny Novgorod provided an excellent opportunity to construct one (Edemskaya and Agkathidis 2015).

The tower that was erected for the 1898 exhibition reached a height of only 25 meters. In comparison to the Eiffel Tower, which soared to a height of 324 meters, the Shukhov tower was not impressive. But Shukhov did not end his research into the hyperbolic paraboloid surface with the Nizhny Novgorod tower. In 1919, he designed a radio tower in Moscow using the hypar. Known as the Shukhov Tower, the structure was initially designed to rise to $350 \mathrm{~m}$ (Fig. 6). In this tower, Shukhov challenged the Eiffel Tower in two ways: first, he wanted to build a tower that would be higher and second, he wanted his tower to weigh less (the Eiffel Tower weighed around 7300 tons). Shukhov's radio tower, rising to $350 \mathrm{~m}$, slightly higher than the Eiffel Tower, was supposed to weigh only 2200 tons. It is true that the 
Fig. 6 Shukhov Tower.

Architect: Vladimir Shukhov

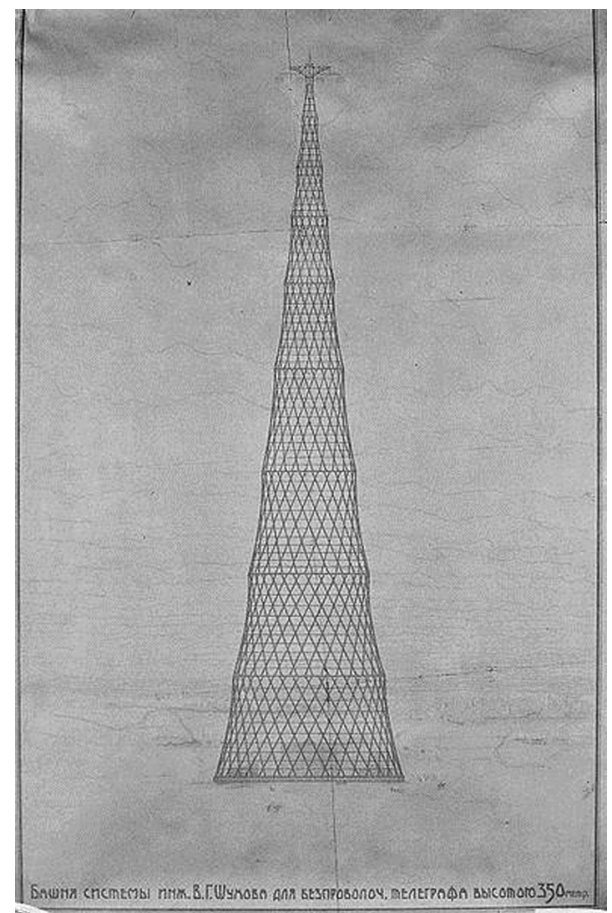

Eiffel Tower was designed to allow people to climb to its top and the Shukhov tower was intended to provide broadcast transmission services-yet Shukhov wanted to exceed Eiffel's achievements. Thus, Shukhov planned to exploit the diagrid nature of the hyperbolic paraboloid surface to construct a lighter and higher tower. Not only was he eager to save money on construction materials, but he also wanted the structure not to seem heavy. The diagrid nature of the hyperbolic paraboloid structure that Shukhov designed allowed the wind to blow right through the tower's rods. Consequently, the expected parallel load was lower and its bearing load was diminished.

Shukhov had no luck with this project. The Russian civil war of the 1920s led to a severe shortage of steel, forcing Shukhov to compromise and reduce the height of his tower in order to be able to construct it at all. ${ }^{1}$ The final result was a tower rising to a total height of 160 meters, whose base was 40 meters in diameter, which was erected for the use of the Moscow radiotelegraph station, and television and radio broadcasting (Fig. 7). The highest point to which visitors could ascend was 148.5 meters off the ground. Yet even though the structure's execution did not reflect its entire initial design, the Shukhov Tower became highly popular and was often used in Russian media as a symbol of the nation's achievements. The tower was featured

\footnotetext{
1 The Russian Civil War followed the Russian Revolution of 1917 and lasted five years till 1922. The War was between the Red Army, fighting for the Bolsheviks, and the White Army, who tried to defend the monarchy. The Red Army defeated the White Army first in the south of Russia and on the front in Ukraine in 1919, and then between 1920 and 1922 in central Russia.
} 


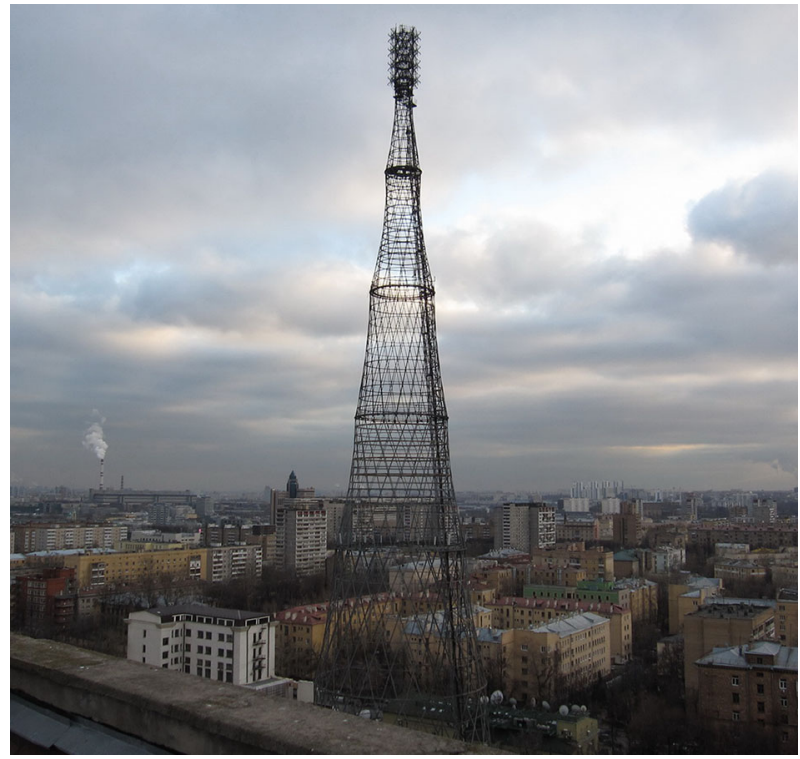

Fig. 7 Shukhov Tower

mainly as a symbol of Russian broadcasting services and was printed on stamps, envelopes and other publications. It also gained credibility as an art piece. In several international exhibitions, such as the "The Art of Engineering" exhibition at the Pompidou Center in Paris in 1997, and in the exhibition "The Best Constructions and Buildings of Twentieth Century Architecture" at the Pinakothek in Munich in 2003, the Shukhov Tower was presented as an engineering artwork. The tower's recognition as an art piece is not surprising. As Andrew Saint showed in his seminal book Architect and Engineer: a Study of Sibling Rivalry, many engineers were occupied with design tasks during the late nineteenth century. Architecture and civil engineering were not dissociated from each other (Saint 2007). Accordingly, Shukhov related to the design of the tower not only as an engineering problem that had to address the structure's functional and construction issues, but also as a design task. In April 2006, at an international conference on world heritage buildings in Moscow, more than two hundred architectural and engineering experts recognized the Shukhov Tower as a world heritage building.

Shukhov's projects were not the end of the idea of a hyperbolic paraboloid tower. Several more attempts were made to construct such towers; the two most prominent examples are the Kobe Port Tower, which was inaugurated in 1963 in Japan (Fig. 8), and Canton Tower in Guangzhou, China, which opened in 2010 (Fig. 9). Both towers used hyperbolic paraboloid structures that include more complex architectural programs than the Shukhov Tower proposed. The 108-meter-high Kobe Port Tower is topped by an observation deck (Denny 2010). Nikken Sekkei, the Japanese architectural firm that designed the tower, was seeking an exceptional structure that would become the city's symbol and the hyperbolic paraboloid 
Fig. 8 Kobe Port Tower.

Architect: Nikken Sekkei

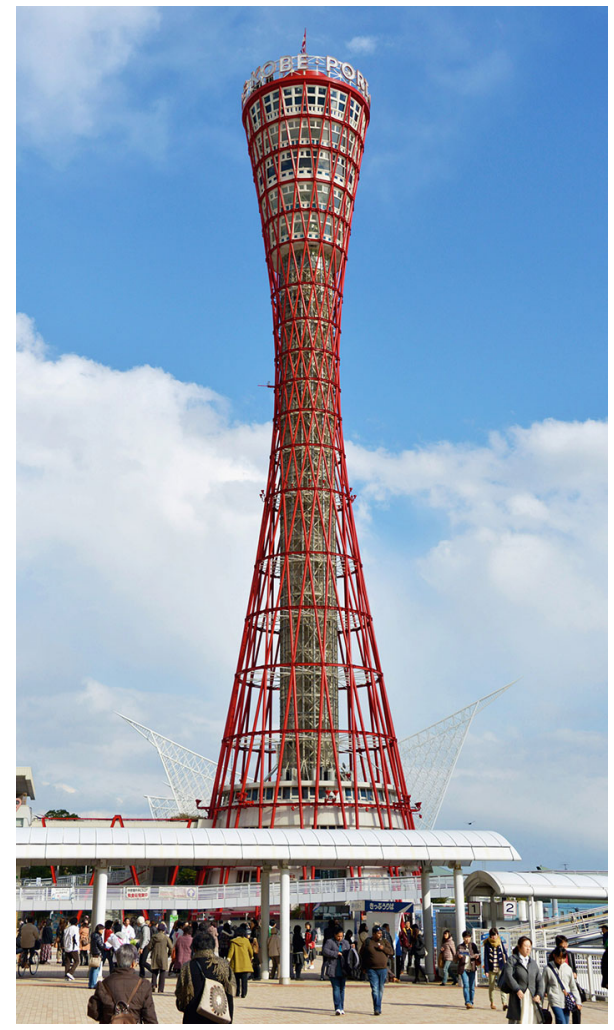

structure provided a suitable solution (Umemiya 2005: 127). The Dutch architects Mark Hemel and Barbara Kuit, and the structural engineer Joop Paul of the structural engineering company ARUP, designed the Canton Tower for the XVI Asiad, also known as the 2010 Asian Games. Six hundred meters high, this tower included an observation deck, TV and radio transmission facilities, restaurants, exhibition spaces, shops and cinemas. For just one year, the Canton Tower was considered the tallest in the world (Hemel and Kuit 2013).

The use of the hyperbolic paraboloid surfaces in the Shukhov Tower, the Kobe Port and Canton Towers proposes a symbolic utilization of the structure that differs from that of the Lightfall. In the towers, the shape is used as a structure and as an envelope for the towers' skins but does not function as a sign of the ways in which the towers should be used, programmatically or otherwise. Instead, on the symbolic level, the three towers propose mainly to demonstrate the structural abilities of the hyperbolic paraboloid shape, its ability to rise to great heights and carry heavy loads. As an engineer, Shukhov naturally was occupied with the structural properties of the shape and wanted to demonstrate it in his structure. Nikken Sekkei, as well as Hemel and Kuit, followed suit. 
Fig. 9 Canton Tower.

Architects: Mark Hemel and

Barbara Kuit

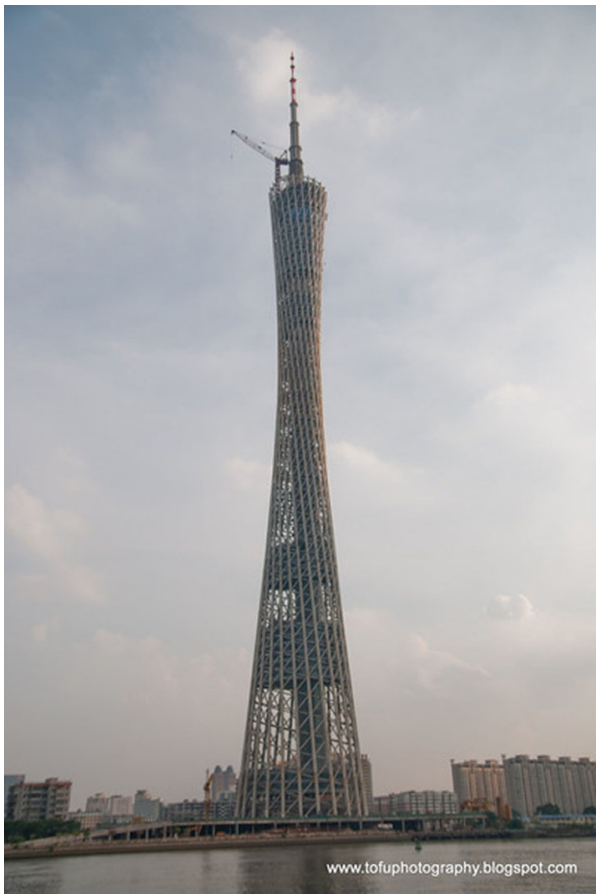

\section{Le Corbusier and Iannis Xenakis and the Figuration of the Hyperbolic Paraboloid Surface}

One of the most interesting uses of the hyperbolic paraboloid structure can be found in the work of Le Corbusier and Iannis Xenakis, who worked in the grandmaster's studio and often collaborated with him. Le Corbusier and Xenakis first used the surface in 1952 for the construction of the Assembly Hall in the Parliament building in Chandigarh, the capital of India's Punjab province (Fig. 10). Several years later, at Expo 58 in Brussels, they multiplied the surface and composed the spectacular Philips Pavilion out of seven hypars (Fig. 11).

Le Corbusier was commissioned to plan the capital of Punjab in 1951. He devoted the bulk of his attention to the urban grid plan that he devised for the city (Boesiger and Girsberger 2000). Yet special attention was also given to the governmental complex that included the Palace of Assembly building, the Secretariat building and the High Court House (Prakash 2002). In all these buildings, Le Corbusier demonstrated his ability to design amorphous shapes. The most outstanding, however, was the Palace of Assembly and its hyperbolic paraboloid shell that enveloped the assembly hall itself. The building as a whole consisted of a long portico, the assembly hall and the offices and rooms that were organized around the hall (Fig. 12). Le Corbusier concentrated on the portico and the assembly hall because they constituted the building's main function (the 


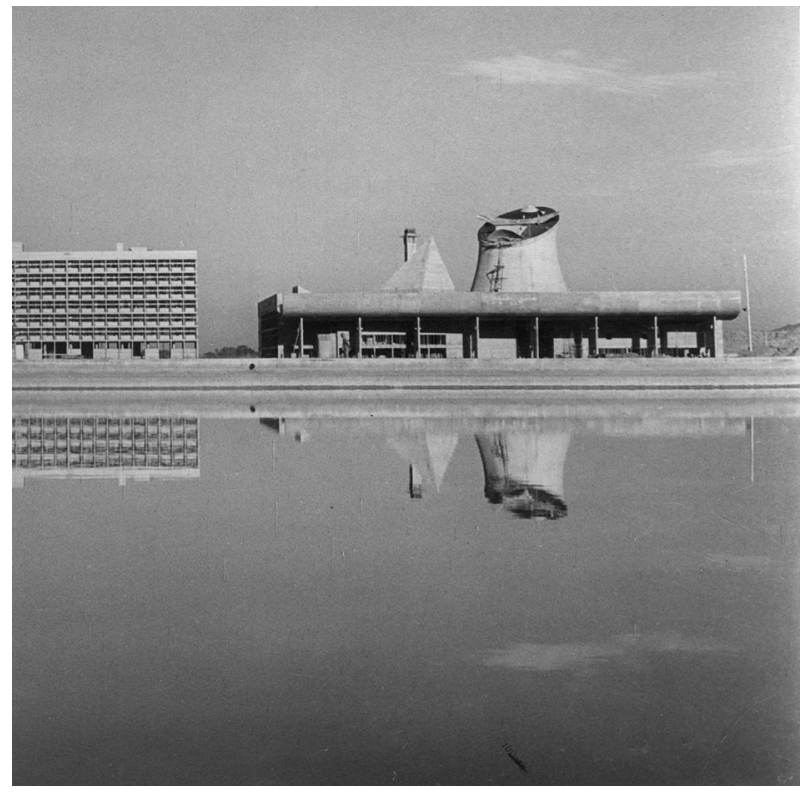

Fig. 10 Assembly Hall, Chandigarh. Architect: Le Corbusier

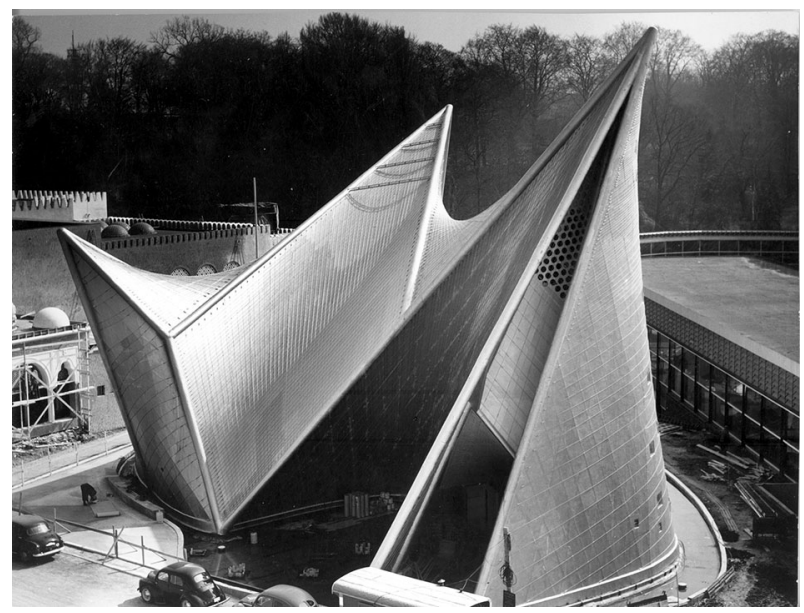

Fig. 11 Philips Pavilion. Architect: Le Corbusier

assembly hall) and its main façade (the portico), which represented the building's overall concept (Cohen 2004).

Le Corbusier therefore treated each of these two main elements in a similar yet different manner; both were symbols, but while the portico derived its shape from a direct figurative reference, the design of the assembly hall originated in mathematics. The portico is composed of eight perforated walls that carry a huge canopy. 


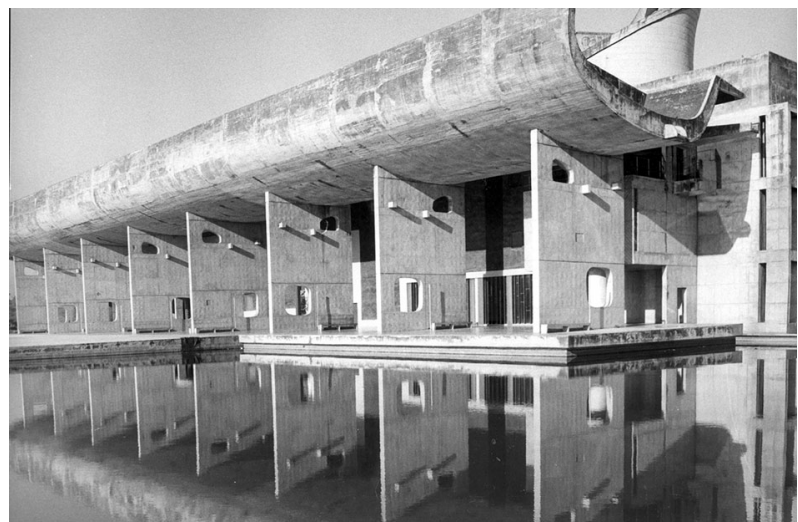

Fig. 12 Assembly Hall, Chandigarh. Architect: Le Corbusier

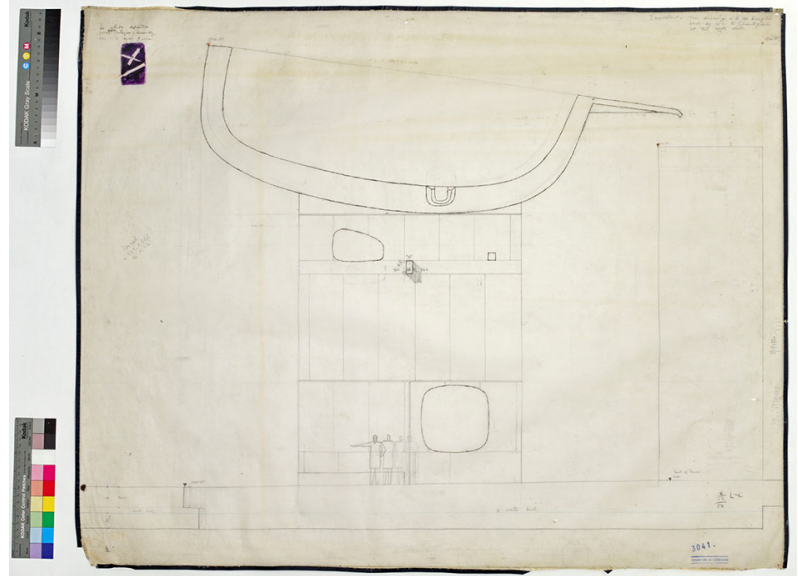

Fig. 13 Bull's horn in Le Corbusier's design

Interestingly, in his design for the canopy section that runs along the building's entire length, Le Corbusier referred to the shape of bull's horns and formed this architectural element as a figurative symbol (Fig. 13). In Indian culture, bull's horns are a symbol of power (Dallapiccola 2002). Thus, Le Corbusier wanted to signify the power inherent in the palace and portray it in the building's façade. The assembly hall, on the other hand, was not directly devised in relation to a figurative reference. Le Corbusier, following Xenakis' exploration of the form, maintained the mathematical rationale of the hyperbolic paraboloid shape and did not manipulate it and transforming it freely. He used the surface as a mathematical shape as defined in the hyperbolic paraboloid formula, and not as a free form. Yet at the same time, Le Corbusier did not treat the outcome of the mathematical shape as an end result. Instead, he attempted to contextualize the mathematical shape using symbolic tools to explain it as a figure. In several sketches, from November and December of 1955 , 


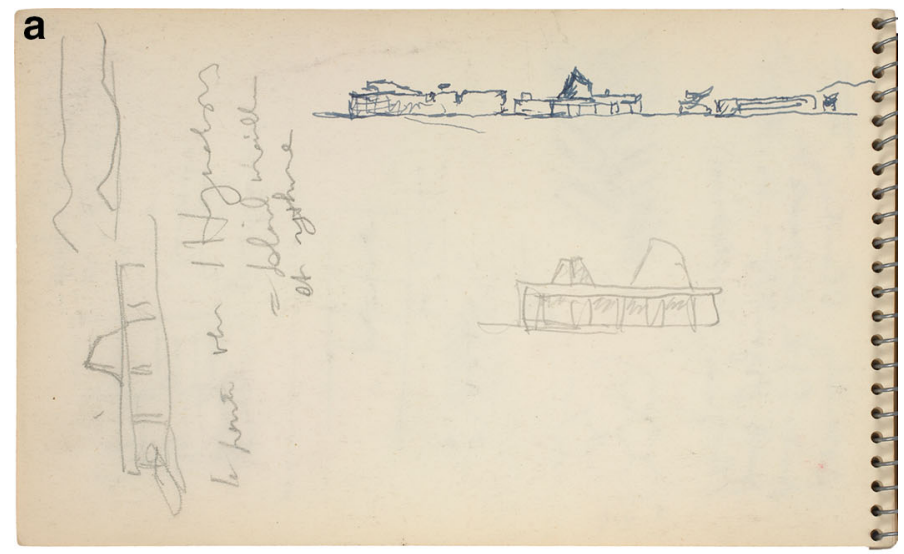

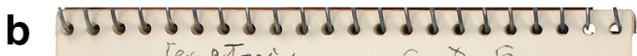

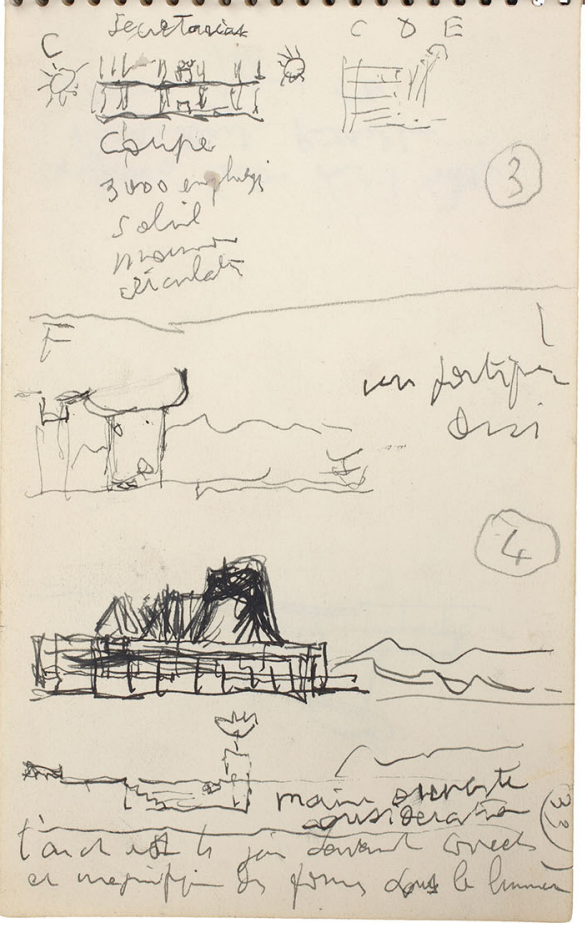

Fig. 14 a, b Sketches of the Assembly Hall with the Himalaya Mountains by Le Corbusier. In the lower sketch, Le Corbusier examined the rhythm that the hyperbolic paraboloid and the mountains create together

he examined the conoid shape of the hyperbolic paraboloid structure of the Assembly Hall in relation to the Himalaya Mountains that formed the building's backdrop (Fig. 14a, b) (Corbusier et al. 1982). For him the shape of the Assembly Hall's hyperbolic paraboloid surface resembled the mountains in the background and helped the structure blend into its environment. 
Le Corbusier's contemplation regarding the figurative nature of the architectural surface was not unique to the Assembly Hall in Chandigarh. As Robin Evans showed in his seminal book The Projective Cast, Le Corbusier already was speculating about the use of figurative forms, whether free-form or mathematical, when he designed the chapel of Notre-Dame du Haut in Ronchamp, France. In Ronchamp, he was not certain about how the chapel's roof should be constructed. Eventually, he decided on a free-form roof. In the Assembly Hall in Chandigarh, Le Corbusier and Xenakis used the mathematical form. Covered by a 15-centimeterthick concrete shell, (Evans 1995) the shape of the assembly hall highlights the plasticity of the surface and provides a unique spatial quality. He added symbolic attributes to the hall's hyperbolic paraboloid surface, first by referring to the form as a mountain and then by installing symbols from Indian cosmology on the oblique roof of the shell.

In the Philips Pavilion, Le Corbusier used the hyperbolic paraboloid surfaces as an architectural element that reflects the latest technological and engineering achievements. For the 1958 Brussels World Fair, Le Corbusier was asked by the Dutch electronics company Philips to design their pavilion in the Dutch section of the fairground. Thus, they were associated with the Dutch electronics industry, but were also perceived as a private enterprise (Trieb 1996). Le Corbusier was asked to devise the architectural side of the pavilion; nevertheless, he did not limit himself and conceptualized the pavilion's internal and external parts, with curved surfaces on which images could be projected. In the late 1950s, however, Le Corbusier was mostly occupied with the design and execution of Chandigarh. Thus he made only the initial sketch of the pavilion and it was Xenakis who worked on the development of the structure and the shell, based on the sketch (Xenakis 1992). Constructed of nine hyperbolic paraboloid surfaces, the shells enveloped an inner space that was often symbolically compared by Le Corbusier to a belly. Visitors entered the "belly" where they could watch eight minutes of moving images selected by Le Corbusier and listen to eight minutes of a sound installation composed by Edgar Varese (Fig. 15a, b). The shell itself was not cast on site. Unlike most hyperbolic paraboloid surfaces, the Philips Pavilion hyperbolic paraboloid surfaces were precast in smaller units that were brought in and assembled on site (Capanna 2001).

The 1958 Brussels World Fair was the first post-World War II international exposition. Its general theme was to show the rejuvenation of mankind and the reconstruction of the world after the war's horrendous destruction (Smits and Jansen 2002). The use of the cast-concrete hyperbolic paraboloid surfaces fit in well with the overall theme as it reflected the ingenuity and technological progress of civil engineering at the time. Philips used these technologies as a means of associating the pavilion with the company's achievements in electronic engineering. The company chose to present its technological accomplishments not by displaying the state-of-the-art appliances and devices it had developed (such as X-ray machines, fluorescent light bulbs and color television sets), but rather by creating a multimedia installation in a unique structure that would impress visitors with its advanced technical capabilities. The symbolic value of the structure, its strong external image, and its internal image as a "belly," worked together to create a total experience for the user. 


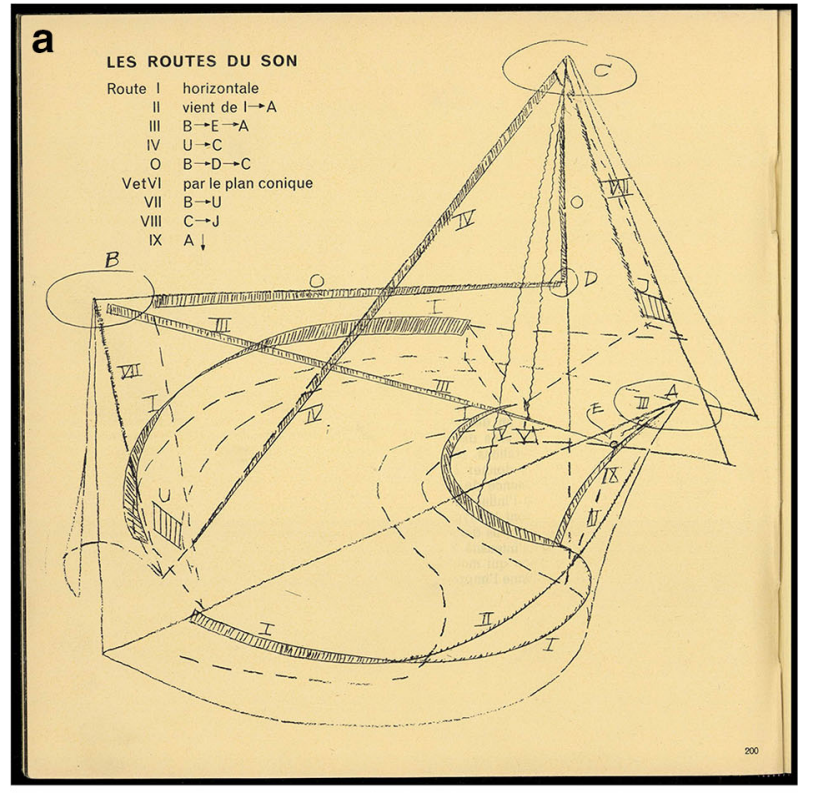

\section{b}

$\frac{2 \text { C PROTET }}{\text { Toutes les surfaces du } 1 \text { er projet }}$

Toutes les surfaces du paraboloides-

Hyperboliques à $l^{\prime}$ exception d'une:le come $L$.

Hyperboliquas a llexception d'une

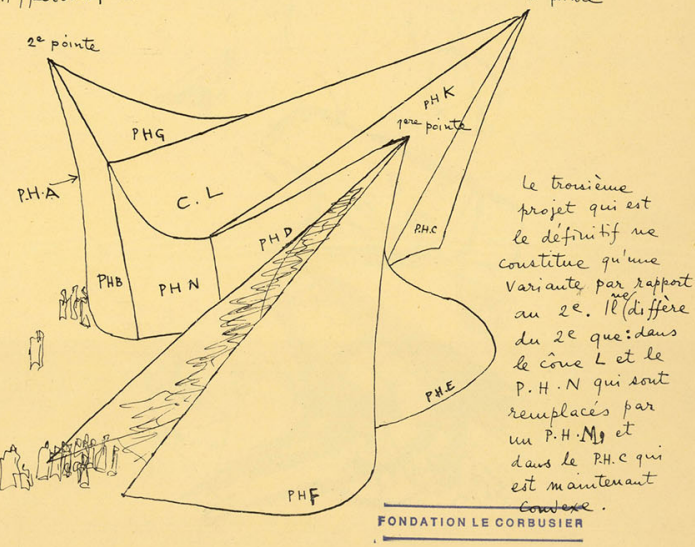

Fig. 15 a, b Philips Pavilion, design stages. Architect: Le Corbusier

The Philips Pavilion drew a mixed reception. Howard Taubman of The New York Times thought the pavilion was the strangest building in the Brussels Expo (Taubman 1958). Others, mostly European architectural critics, thought the building was fascinating and that the integration of various mediums-light, sound and architecture - in one structure was innovative and creative. Today scholars of new 
media see the Philips Pavilion as one of the first installations in the field (Von Moos 2009). In any case, the building — one of the fair's most-visited pavilions-grabbed the attention of the architectural world and presented a new way to implement the hyperbolic paraboloid surface.

It was the pavilion's unique shape that created such a stir. In the postwar years, Le Corbusier's occupation with the shape of architecture differed from his approach during the prewar years. After the war, Le Corbusier devised the shapes of several buildings in relation to their figuration and not only as a functional form. To that end, the implementation of the hyperbolic paraboloid surface as a figure was not different to other work he was doing at the time. Here, Le Corbusier also tried to rationalize the form as a figure. It was both one of his first references to this specific mathematical shape - the hyperbolic paraboloid surface-as figures and one of the only times Le Corbusier used mathematical shapes to create figurative forms.

\section{The Mathematical Symbols of Architecture}

The symbolic use of a mathematical form such as the hyperbolic paraboloid surface raises some questions regarding the symbols of architecture. That is because the mathematical form was not conceived initially as a symbol, but instead as a mathematical function that allows for the creation of a curvilinear shape relatively easily (by using only shifting straight lines). Thus, unlike other symbols of architecture, the hyperbolic paraboloid surface did not stem from a search for a symbol in and of itself. It was first conceived as a mathematical function and only then was it appropriated as a symbol.

This means that, unlike symbols that were conceived as such from the outset, the symbolic use of the hyperbolic paraboloid surface lies somewhere between the mathematical and the symbolic. On the one hand, it represents a mathematical idea of ingenuity and, on the other hand, as a symbol, it alludes to external references. The in-between position of the mathematical symbol creates a new type of symbol in architectural representations, because the mathematical symbol is formally rigorous (as befits a mathematical function) and yet, at the same time, it can be based in visuality. Therefore, the mathematical symbol goes beyond the "regular" architectural symbol, because it does not stem solely from visual attributes but also from methods that are based in accuracy and precision.

In that respect, the hyperbolic paraboloid surface in its various manifestationsfigurative (e.g., the Assembly Hall in Chandigarh and the Philips Pavilion); demonstrative (e.g., the Shukhov Tower); and operative (e.g., Cohen's Lightfall) expands the meaning of the mathematical symbol in architecture and the relation between the mathematical and visual aspects of the symbolic shape. As a figurative manifestation, the symbolic role of the hyperbolic paraboloid surface is obviousthe mathematical surface is being directly appropriated as a symbol that addresses only the visual properties of the shape. As a demonstrative manifestation, the hyperbolic paraboloid surface functions as a symbol that unites the shape's mathematical-structural properties with its visual ones, because the mathematical- 
structural idea becomes the symbol that is being demonstrated by the form's visual aspects.

The hypar's operative symbolic manifestation is the most complex of the three, because it is a case in which the symbol goes beyond the mathematical shape and ventures into an instructive form. What started as a physical manifestation of the mathematical formula and then acts as a symbol that unites the mathematical and the visual now becomes a sign that shows us how to use the space. Thus the mathematical symbol does not remain merely an image and a sign; it is transformed into a mechanism that operates and gives directions to the body.

The Lightfall clearly manifests this transformation as its symbolism functions to index the relations between the galleries and the hyperbolic paraboloid surfaces, showing users how to circulate in the building.

\section{References}

Barrallo, Javier and Santiago Sánchez-Beitia. 2011. The Geometry of Organic Architecture: The Works of Eduardo Torroja, Felix Candela and Miguel Fisac. In: Bridges 2011: Mathematics, Music, Art, Architecture, Culture, 70-71. San Sebastián: The University of the Basque Country.

Beltrami, E. 1868. Saggio di interpretazione della geometria non-euclidea. In: Giornale di Mathematiche VI, 285-315. Firenze: Annali di Matematica Pura ed Applicata.

Bennett, T. 1994. The Exhibitionary Complex. In: Culture/Power/History: A Reader in Contemporary Social Theory, eds. Nicholas B. Dirks, Geoff Eley, and Sherry B. Ortner, 123-154. Princeton: Princeton University Press.

Boesiger, W. and H. Girsberger. 2000. Le Corbusier: 1910-65. Editorial Gustavo Gili.

Capanna, A. 2001. Iannis Xenakis: Architect of Light and Sound. In: Nexus Network Journal, 3 (1): 19-26.

Cohen, J. L. 2004. Assembly. In: Le Corbusier, 78-79. Los Angeles: Taschen.

Cohen, P. S., 2001. Contested Symmetries: And Other Predicaments in Architecture. Princeton: Princeton Architectural Press.

Cohen, P. S. 2007. Elegance, Attenuation, and Geometry: Herta and Paul Amir Building, Tel Aviv Museum of Art. Architectural Design 77 (1): 54-61.

Cohen, P. S., 2011. In a lecture at Tel Aviv Museum of Art, International Symposium on Contemporary Museum Architecture, 1 November 2011.

Corbusier, L., A. Willis, A. Serenyi, F. de Franclieu and A. Wogenscky. 1982. Le Corbusier Sketchbooks. Architectural History Foundation.

Dallapiccola, A. L. 2002. Dictionary of Hindu Lore and Legend. London: Thames and Hudson.

Denny, M. 2010. Towers of Strengths. In: Super Structures: The Science of Bridges, Buildings, Dams, and Other Feats of Engineering, 78-105. Baltimore: The John Hopkins University Press.

Edemskaya, E. and A. Agkathidis. 2015. Vladimir Shukhov: A Critical Review on Digital Architecture. In: Real Time-Proceedings of the 33rd eCAADe Conference-Volume 1 (Vienna University of Technology, Vienna, Austria, 16-18 September 2015), ed. B. Martens, et al., 395-402 eCAADe 33 Conference Proceedings, 1-8.

English, E. C. 2005. Vladimir Shukhov and the Invention of Hyperboloid Structures. In: Metropolis \& Beyond: Proceedings of the 2005 Structures Congress and the 2005 Forensic Engineering Symposium. http://dx.doi.org/10.1061/40753(171)73. Accessed 7 Sep. 2016.

Evans, R. 1995. Comic Line. In: The Projective Cast, 273-320. Cambridge: MIT Press.

Flügge, W. 2013. Stresses in Shells. Springer Science and Business Media.

Gray, J. J. 2004. János Bolyai, Non-Euclidean Geometry, and the Nature of Space (Vol. 1). Cambridge, Massachusetts: MIT Press.

Hemel, M. and B. Kuit. 2013. Supermodel: Making One of the World's Tallest Towers. Rotterdam: 010 Publishers. 
Kolmogorov, A. N. and A. P. Yushkevich. 1996. Beltrami's Interpretation. In: Mathematics of the 19th Century, 67-71. Basel: Birkhauser.

Lavin, S. 2011. Kissing Architecture. Princeton: Princeton Architectural Press.

Lobachevsky, N. 1830. A Concise Outline of the Foundations of Geometry. St. Petersburg: St. Petersburg Academy of Sciences.

Papadopoulos, A. 2010. On Hyperbolic Geometry and its Reception. In: Pangeometry, 260-279. Zurich: European Mathematical Society.

Picon, A. 1997. L'art de l'ingenieur: constructeur, entrepreneur, inventeur. Paris: Éditions du Centre Georges Pompidou.

Picon, A. 2010. Digital Culture in Architecture: An Introduction for the Design Professions. Basel: Birkhauser.

Prakash, V. 2002. Chandigarh's Le Corbusier: The Struggle for Modernity in Postcolonial India. Seattle: University of Washington Press.

Saint, A. 2007. Conclusion. In: Architect and Engineer: a Study of Sibling Rivalry, 485-493. New Haven: Yale University Press.

Smits, K. and A. Jansen. 2002. Staging the Nation at Expos and World's Fairs. National Identities 14 (2): 173-188.

Taubman, H. 1958. Fairgoers Hear Electronic Poem. New York Times, 21 May, 1958.

Tel Aviv Museum of Art. 2016. http://www.tamuseum.org.il/en/new-building.

Trieb, M. 1996. Space Calculated in Seconds: The Philips Pavilion, Le Corbusier, Edgard Varèse. Princeton: Princeton Architectural Press.

Umemiya, H. 2005. Kobe Port Tower. Japan Architect, (5): 127.

Von Moos, S. 2009. Elements of A Synthesis. In: Le Corbusier: Elements of A Synthesis, 265-321. Rotterdam: 010 Publishers.

Xenakis, I. 1992. Formalized Music: Thought and Mathematics in Composition (No. 6). Pendragon Press. Zalivako, A. 2009. Soviet Avant-Garde-Origin of New Materials and Construction Methods or Extension of Europe's Modern Movement? A Critique. In: Proceedings of the Third International Congress on Construction History (May 20-24, Cottbus, Germany).

Dr. Eran Neuman is an architect and the head of the Azrieli School of Architecture, Tel Aviv University. His books include: Performalism: Form and Performance in Digital Architecture co-edited with Yasha Grobman (2012), Shoah Presence: Architectural Representations of the Holocaust (2014) and David Yannay: Architecture and Genetics (2015). 